\title{
Nasal Floor Slanting and Its Association With Nasofacial Structures
}

\author{
Marn Joon Park ${ }^{(D)}$, Yeonjoo Choi, Chol Ho Shin, and Yong Ju Jang \\ Department of Otorhinolaryngology-Head and Neck Surgery, Asan Medical Center, University of Ulsan College of Medicine, \\ Seoul, Korea
}

비 기저부 비대칭과 비-안면구조물과의 관계 분석

박만준 · 최연주 · 신철호 · 장용주

울산대학교 의과대학 서울아산병원 이비인후-두경부외과학교실

Received June 2,2021

Revised August 11, 2021

Accepted August 17, 2021

Address for correspondence

Yong Ju Jang, MD, PhD

Department of Otorhinolaryngology-

Head and Neck Surgery,

Asan Medical Center,

University of Ulsan

College of Medicine,

88 Olympic-ro 43-gil, Songpa-gu,

Seoul 05505 , Korea

Tel $+82-2-3010-3710$

Fax $+82-2-489-2773$

E-mail jangyj@amc.seoul.kr
Background and Objectives Nasal floor slanting (NFS) is an incidental radiographic finding of asymmetry in the nasal floor level. Despite its frequent appearance, however, NFS has never been properly defined, neither has its correlation with the asymmetry of the adjacent nasofacial structures been investigated. We evaluated the incidence of NFS in patients with sinonasal symptoms and its correlation with the nasofacial skeletal structures.

Subjects and Method We investigated patients who underwent preoperative ostiomeatal unit (OMU) CT and facial photography. We measured the incidence of NFS and its angle in the 265 patient images, and analyzed the relationships between NFS and radiologically detected asymmetries of the adjacent nasofacial skeleton and facial asymmetry visible on a photograph. Results NFS was found in $51 \%$ of the study subjects $(136 / 265)$, who were defined as the slanted group. The mean NFS angle in the slanted group was $7.7^{\circ}$ with a standard deviation (SD) of $4.4^{\circ}$, ranging from $2.4^{\circ}$ to $22.4^{\circ}$. The slanted group showed a higher incidence of nasal septal deviation, asymmetry in the orbit and maxillary sinus, and a larger maxillary cavity ( $p<$ 0.001) than the non-slanted group. Asymmetry of the face showed a higher incidence in the slanted group $(p<0.01)$, whereas an external nasal deviation did not show an association with NFS.

Conclusion NFS is evident in about $50 \%$ of patients complaining of nasal symptoms and is associated with nasofacial skeletal asymmetry as well as asymmetry in the face. Korean J Otorhinolaryngol-Head Neck Surg 2021;64(10):726-33

Keywords Facial asymmetry; Nasal floor; Nasal floor level asymmetry; Nasal floor slanting; Nasal septal deviation.

\section{Introduction}

$\mathrm{CT}$ is an important tool for diagnosing various sinonasal disorders. Upon careful review of the CT images of patients complaining of these conditions, nasal floor slanting (NFS) can be frequently detected in addition to sinus pathologies and

This is an Open Access article distributed under the terms of the Creative Common Attribution Non-Commercial License (https://creativecommons.org/licenses/by-nc/4.0) which permits unrestricted non-commercial use, distribution, and reproduction in any medium, provided the original work is properly cited. septal deformities, particularly in patients with a deviated nose (with its unknown clinical significance). A coronal reconstructed image from a CT scan can be used to detect a level difference between the right and the left side of the nasal floor, i.e. NFS. Despite its frequent occurrence however, NFS has very rarely been defined, studied, or debated. There is currently only one anecdotal report on the endoscopically determined unequal nasal floor level found in $52 \%$ of patients with a deformed nasal septum. ${ }^{1)}$ It is also quite evident that CT imag- 
ing enables an accurate and comprehensive assessment of the nasofacial skeleton. However, no studies using CT have investigated NFS. In our present study, we evaluated the incidence and clinical significance of NFS in terms of its association with septal deviation and facial skeletal asymmetry.

\section{Subjects and Methods}

\section{Study design and patient selection}

We retrospectively reviewed patients between January 2008 and July 2017 complaining of sinonasal symptoms (e.g. nasal obstruction, rhinorrhea, deformed nose) who have taken both the pre-operative facial photograph and ostiomeatal unit (OMU) CT for the scheduled rhinoplasty or septoplasty. Patients younger than 20 years, and any with a history of congenital facial anomaly, traumatic deformity of the nasofacial area, neoplasm of the head and neck area, or CT image obtained from other medical institution, were excluded from further analysis. We additionally excluded patients with a previous surgery for the sinonasal cavity, face, or craniofacial skeleton, or who received dental implants of the upper teeth (Fig. 1).

Informed consent was obtained for all of our included study patients regarding the usage of their facial photographs for subsequent clinical care, investigative purposes, and publication. All of the obtained facial photographs were stored with strict access restriction. The design of the study and the use of personal information were approved by the Institutional Review Board of AMC (approval no. 2017-0948).

A total of 265 patients were finally included in our current analysis, consisting of $202(76 \%)$ males and 63 (24\%) females. The mean age of these patients was $34.5 \pm 13.4$ years, ranging from 2076 years. All 265 patients eventually underwent surgery: 111 (42\%) patients received a septoplasty, 60 (23\%) underwent a septoplasty along with endoscopic sinus surgery (ESS), 74 (28\%) had a rhinoseptoplasty, and 20 (7\%) had a rhinoseptoplasty with ESS (Table 1).

\section{CT images and facial photographs}

All 265 study patients underwent OMU CT scanning. The CT image was captured on a plane parallel to the infraorbitomeatal line. Image reconstruction was done with a slice thickness of $2 \mathrm{~mm}$, both coronally and axially. The CT window was

Table 1. Patient demographics $(n=265)$

\begin{tabular}{lc}
\hline Age (min-max) & $34.5 \pm 13.4(20-76)$ \\
Sex (male/female) & $202(76) / 63(24)$ \\
Description of the performed surgery & \\
Septoplasty only & $111(42)$ \\
Rhinoseptoplasty only & $74(28)$ \\
Septoplasty with ESS & $60(23)$ \\
Rhinoseptoplasty with ESS & $20(7)$ \\
\hline
\end{tabular}

Data are presented as the mean \pm standard deviation or $\mathrm{n}(\%)$. ESS, endoscopic sinus surgery

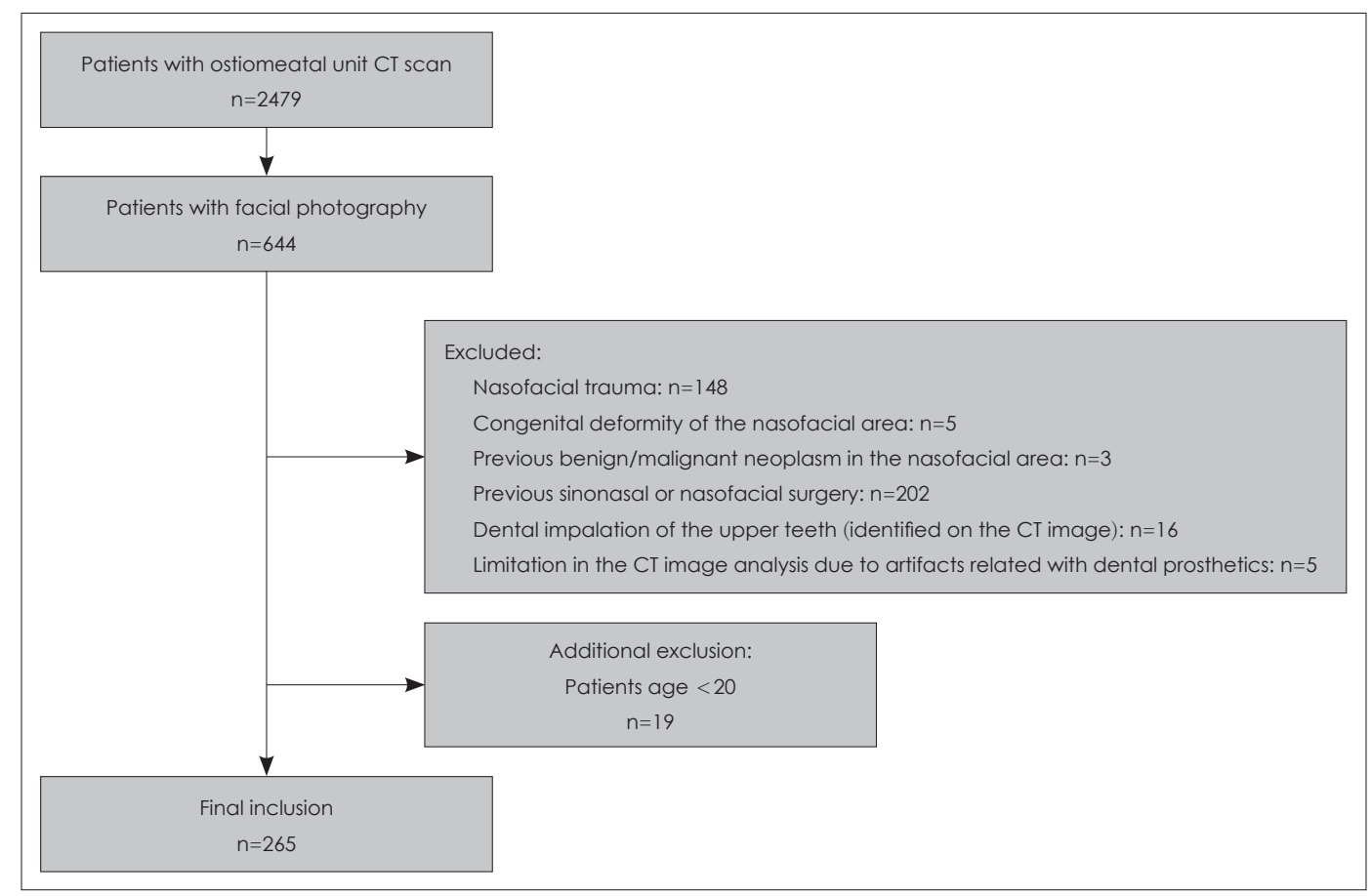

Fig. 1. A flow-chart of the patient selection, and the number of excluded subjects, elaborated in detail. 
set to a width of 2000 and a window level of 200 to yield the optimal visibility of the OMU and nasofacial structures.

All facial photographs of the study patients were taken by the same trained professional using a standardized clinical photography protocol. Briefly, the patients were instructed to sit on a stool in front of a blue colored fabric with their facial muscles relaxed. Eyeglasses, earrings, facial masks, and hats were removed. A full-frontal view of the face was obtained. The camera was installed with a built-in dotted cross, and the center of the cross was focused on the vertical midpoint be-

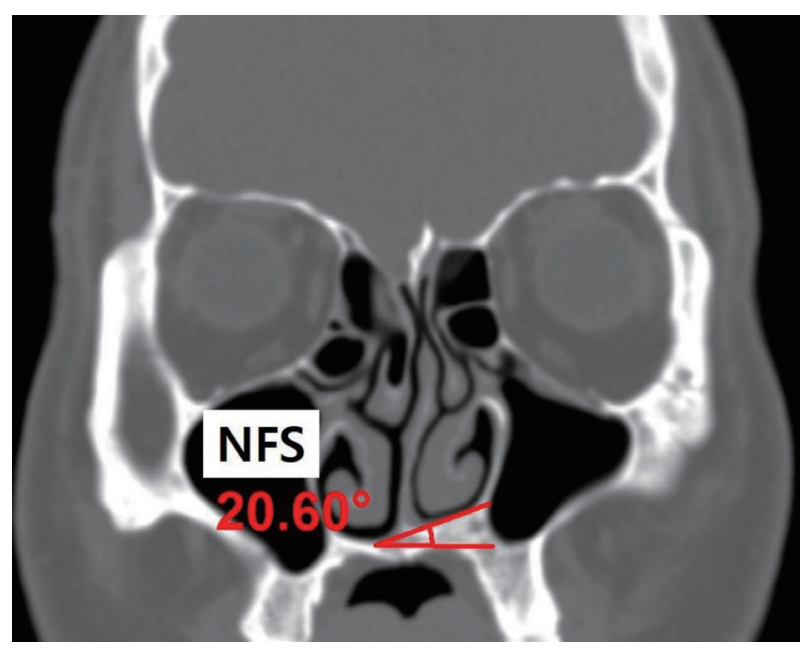

Fig. 2. A coronal ostiomeatal unit CT image is shown on which the most inferior point of the bony nasal floor in each nasal cavity was marked. A horizontal line starting from the marked point was then drawn on either side. Finally, a line connecting the two marked points on each side was made. The angle between these two lines was measured and denoted the 'NFS angle.' In addition, the side of the higher nasal floor was investigated. NFS, nasal floor slanting. tween both pupils. Hence, a slanted or a rotated head position was easily noticeable and could be corrected. The brightness, exposure level, and shutter speed of the camera were equivalent for all patients.

\section{Measurement of NFS and the nasofacial skeleton}

The measurement of NFS and other nasofacial skeleton structures were in the cross-section coronal CT image where the crista gali was visualized was visualized (Fig. 2). First, the most inferior point of the bony nasal floor in each nasal cavity was marked. A horizontal line starting from the marked point was then drawn on either side. Finally, a line connecting the two marked points on each side was made. The angle between the two lines was measured and denoted the 'NFS angle.' In addition, the side of the higher nasal floor was investigated. The patients who showed no level difference of the nasal floor (NFS angle $\leq 2^{\circ}$ ), were categorized as the "nonslanted group', and those with an NFS angle above $2^{\circ}$ as the 'slanted group.'

In the same coronal OMU CT image section from which the NFS was measured, the most inferior point of the orbit (IOr) and the most inferior point of the maxillary sinus (IMS) were marked on both sides (Fig. 3A). In a similar fashion to the NFS measurements, a more superiorly located side for both the IOr and IMS were investigated. A horizontal line starting from each IOr and IMS on either side, and a line connecting each marked point were drawn. The angles between these lines were then measured, defined as the IOr angle and
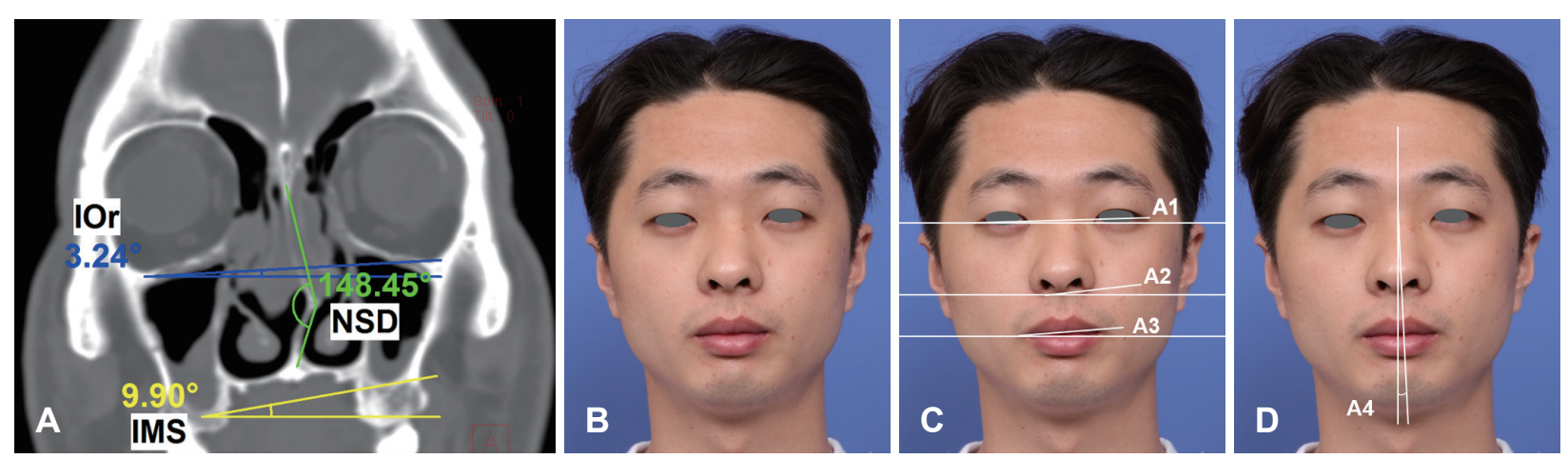

Fig. 3. Measurement of the nasofacial structures. A: Measurement of nasofacial skeletal structures using an OMU CT image. The IOr base and IMS base were marked on both sides. In a similar fashion to the NFS measurement, the angle between these two lines, the 'NSD angle,' was measured. The most protruded point of the bony nasal septum was marked, and the angle formed by the lines from the marked point to the center of the cribriform plate and maxillary crest was calculated. B: Facial photograph of the same patient in the OMU CT scan. C: To investigate the horizontal level asymmetry of the face, the lateral canthus, the most inferior point of the alar base, and the lateral angular margin were marked on both sides. In the same manner as the NFS angle measurement, a horizontal line was drawn on one point, and a line connecting both landmarks was then drawn. The angle between these two lines were measured, and was defined as A1-3, representing the upper, middle, and lower face, respectively. The patient was considered to have a horizontal facial asymmetry when the $A 1, A 2$, or $A 3$ angle showed slanting, i.e. was above $0^{\circ}$. D: The presence of an external nose deviation was determined when the angle between the nasion-tip and the nasion-glabella line was above $0^{\circ}(\mathrm{A} 4)$. OMU, ostiomeatal unit; IOr, most inferior point of the orbit; IMS, most inferior point of the maxillary sinus; NFS, nasal floor slanting; NSD, nasal septal deviation. 
IMS angle. The side of the bony nasal septal deviation (NSD) was investigated also. To measure the NSD angle, the most protruded point of the bony nasal septum was marked, and the angle formed by the lines from the marked point to the center of the cribriform plate and maxillary crest were measured. In patients with an s-shaped bony nasal septum deformity, the side of the more protruded bony septum was considered to the side of the NSD. A definition of a positive NSD was defined by an NSD angle of more than $170^{\circ}$, in reference to the previous studies on the NSD. ${ }^{2,3)}$ In addition, the volume of the maxillary sinus on the CT image was measured using the planimetry method, in parallel with the previous report. ${ }^{4)}$ A definition of a significant asymmetrical maxillary sinus volume was defined when the ratio between the right- and the left-side volume was less than 0.9 or over 1.1. To investigate the presence of horizontal facial level asymmetry on the frontal image of the facial photographs (Fig. 3B), three facial landmarks were defined as representative of the upper, middle, and the lower subunits of the face. The lateral canthus was employed to represent the upper part of the face, the inferior margin of the alar base the middle part, and the lateral angular margin was used to indicate the lower portion of the face and was marked on both sides (Fig. 3C). In parallel with the NFS angle measurement, a horizontal line was drawn on each point, and a line connecting both landmarks was drawn. The angles between two lines were measured, and were defined as A1-3, each representing the upper, middle, and lower face, respectively. If the measured angle was above $0^{\circ}$, then an asymmetry of each subunit was considered to be present. The subjects were considered to possess a horizontal facial asymmetry when more than one of the values $(\mathrm{A} 1-3)$ was over $0^{\circ}$. The presence of an external nose deviation was determined as follows: the angle between the nasion-tip and the nasion-glabella line was defined as A4, and the subject was considered to have a deviat- ed nose if this angle was over $0^{\circ}$ (Fig. 3D).

MB-Ruler Pro (version 5.0; Markus Bader-MB Software Solutions; Hügelsheimer, Iffezheim, Germany) was used to measure each angle. Evaluations of the facial photographs was conducted prior to the CT image evaluation. In addition, the investigator of the CT images was blind to the facial photograph findings.

\section{Statistical analysis}

A chi-square test was used to compare the proportion of different study parameters between the groups. A Student's t-test was used to compare the mean values for each anthropometric parameter between the non-slanted and slanted groups. Correlation analysis was conducted to assess the correlations between the NFS and NSD angles, and the IOr and IMS angles. All of these statistical analyses were conducted SPSS software for Windows (version 17.0; SPSS Inc., Chicago, IL, USA). Significance was set at a $p$ value $<0.05$.

\section{Results}

The incidence of NFS in our current study cohort was $51 \%$ (136/265 patients). A higher nasal floor on the left side was observed in $72(52 \%)$ of these patients and on the right side in 64 cases (48\%). Among these 136 patients with an NFS angle above $2^{\circ}$ (the slanted group), the mean slant angle was $7.7^{\circ} \pm$ $4.4^{\circ}$, ranging from $2.4^{\circ}$ to $22.4^{\circ}$.

The slanted group showed a higher proportion of cases of a bony NSD, IOr, or IMS, with maxillary sinus size differences, and with horizontal facial asymmetry (all $p$ value $<0.05$ ) (Table 2). Moreover, the mean NSD angle in the slanted group was $155.2^{\circ} \pm 9.77^{\circ}$, compared to $162.4^{\circ} \pm 9.24^{\circ}$ in the non-slanted group $(p<0.001)$, indicating a propensity for a more-deviated bony nasal septum in patients with NFS (Table 3 ). Simi-

Table 2. NFS and its correlation with nasofacial characteristics

\begin{tabular}{|c|c|c|c|c|c|c|}
\hline & \multicolumn{4}{|c|}{ Radiographic findings } & \multicolumn{2}{|c|}{ Photographic findings } \\
\hline & $\begin{array}{l}\text { Nasal septal } \\
\text { deviation }\end{array}$ & $\begin{array}{l}\text { Orbital } \\
\text { base level } \\
\text { asymmetry }\end{array}$ & $\begin{array}{l}\text { Maxillary sinus } \\
\text { base level } \\
\text { asymmetry }\end{array}$ & $\begin{array}{c}\text { Maxillary sinus } \\
\text { volume } \\
\text { asymmetry }\end{array}$ & $\begin{array}{l}\text { Horizontal } \\
\text { facial } \\
\text { asymmetry }\end{array}$ & $\begin{array}{c}\text { External nasa } \\
\text { deviation }\end{array}$ \\
\hline All patients $(n=265)$ & $210(79.2)$ & $117(44.2)$ & $134(50.6)$ & $79(29.8)$ & $81(30.6)$ & $186(79.0)$ \\
\hline $\begin{array}{l}\text { Non-slanted group } \\
\left(\text { NFS angle } \leq 2^{\circ}\right)(n=129)\end{array}$ & $89(69.0)$ & $16(12.4)$ & $19(14.7)$ & $60(44.1)$ & $30(23.3)$ & $89(69.0)$ \\
\hline $\begin{array}{l}\text { Slanted group } \\
\qquad\left(\text { NFS angle }>2^{\circ}\right)(n=136)\end{array}$ & $121(89.0)$ & $101(74.3)$ & $115(84.6)$ & $19(14.7)$ & $51(37.5)$ & $97(71.3)$ \\
\hline$p$ value* & $<0.001$ & $<0.001$ & $<0.001$ & $<0.001$ & 0.01 & 0.68 \\
\hline
\end{tabular}

All values are presented as the number of patients (\%). *p values were calculated using the chi-square test or Fisher's exact test to compare the incidence of each parameter between the non-slanted and slanted groups. NFS, nasal floor slanting 
larly, a larger IOr angle $\left(1.7^{\circ} \pm 1.35^{\circ}\right.$ in the slanted group and $0^{\circ} \pm 0.80^{\circ}$ in the non-slanted group) and IMS angle $\left(3.5^{\circ} \pm 3.10^{\circ}\right.$ in the slanted group and $0^{\circ} \pm 1.98^{\circ}$ in the non-slanted group) was found among the NFS cases (both $p$ value $<0.001$ ). In contrast, there were no significant difference between the measured angles at the upper, middle, and lower facial subunits between the slanted and non-slanted group.

A significant positive correlation was found between both the IOr and IMS angles and the NFS angle, indicating that patients with a higher NFS angle tended to also have a higher IOr and IMS angle (Fig. 4A and B). By contrast, a significant negative correlation was evident for the NSD and NFS angles, indicating that the patients with a greater NFS angle will likely have a more severe deviation of the nasal septum (lesser NSD angle) (Fig. 4C).

The rate of each investigated parameter corresponding to the direction of the NFS in the 136 study patients showing a slanted nasal floor (Table 4). The lateral canthal and lateral angular margin levels were found to be higher on the side of the higher nasal floor, but this was not observed at the alar base margin. The direction of the external bony nose deviation showed no difference in accordance with the presence or side of the higher nasal floor. NFS cases with a higher location of the orbit and maxillary sinus on the higher nasal floor side were predominant, whereas the direction of the bony septum deviation was predominantly on the side of the lower nasal floor in these patients.

A representative NFS patient with a higher nasal floor on the right side, along with a higher location of the orbit and maxillary sinus, in addition to a smaller maxillary sinus, on the right side as in Fig. 5. All four study authors judged that this patient had a higher-looking face on the right side. The lateral canthus margin and the lateral lip margin in these cases showed a higher placement on the right side, whereas there was no level difference at the alar base.

\section{Discussion}

The irregular shape of the maxilla bone and its relationship to a deformed nasal septum had been investigated in a number

Table 3. Anthropometric differences according to the presence of NFS

\begin{tabular}{|c|c|c|c|c|c|c|c|c|}
\hline & \multicolumn{4}{|c|}{ Radiographic findings } & \multicolumn{4}{|c|}{ Photographic findings } \\
\hline & NSD angle, ${ }^{\circ}$ & $\begin{array}{l}\text { IOr } \\
\text { angle, }^{\circ}\end{array}$ & $\begin{array}{c}\text { IMS } \\
\text { angle, }^{\circ}\end{array}$ & $\begin{array}{l}\text { Maxillary sinus } \\
\text { volume } \\
\text { differences }(\mathrm{mL})\end{array}$ & $A 1, \circ$ & $A 2, \circ$ & $A 3, \circ$ & $A 4, \circ$ \\
\hline All patients $(n=265)$ & $\begin{array}{c}158.7 \\
(152.2-165.7)\end{array}$ & $\begin{array}{c}0.0 \\
(0.0-1.9)\end{array}$ & $\begin{array}{c}0.6 \\
(0.0-4.2)\end{array}$ & $\begin{array}{c}0.63 \\
(0.33-1.17)\end{array}$ & $\begin{array}{c}0.7 \\
(0.2-1.0)\end{array}$ & $\begin{array}{c}1.1 \\
(0.1-2.1)\end{array}$ & $\begin{array}{c}1.1 \\
(0.4-1.9)\end{array}$ & $\begin{array}{c}0.7 \\
(0.4-4.0)\end{array}$ \\
\hline $\begin{array}{l}\text { Non-slanted group } \\
\left(\text { NFS angle } \leq 2^{\circ}\right)(n=129)\end{array}$ & $\begin{array}{c}162.4 \\
(155.7-170.5)\end{array}$ & $\begin{array}{c}0.0 \\
(0.0-0.0)\end{array}$ & $\begin{array}{c}0.0 \\
(0.0-0.0)\end{array}$ & $\begin{array}{c}0.46 \\
(0.28-0.7)\end{array}$ & $\begin{array}{c}0.7 \\
(0.2-1.0)\end{array}$ & $\begin{array}{c}1.1 \\
(0.2-2.2)\end{array}$ & $\begin{array}{c}1.2 \\
(0.5-1.9)\end{array}$ & $\begin{array}{c}0.7 \\
(0.4-4.0)\end{array}$ \\
\hline $\begin{array}{l}\text { Slanted group } \\
\qquad\left(\text { NFS angle }>2^{\circ}\right)(n=136)\end{array}$ & $\begin{array}{c}155.2 \\
(150.4-161.0)\end{array}$ & $\begin{array}{c}1.7 \\
(0.3-2.5)\end{array}$ & $\begin{array}{c}3.5 \\
(2.1-5.1)\end{array}$ & $\begin{array}{c}1.03 \\
(0.45-1.87)\end{array}$ & $\begin{array}{c}0.6 \\
(0.2-1.1)\end{array}$ & $\begin{array}{c}1.0 \\
(0.0-2.0)\end{array}$ & $\begin{array}{c}1.0 \\
(0.2-1.9)\end{array}$ & $\begin{array}{c}0.6 \\
(0.3-2.4)\end{array}$ \\
\hline p value* & $<0.001$ & $<0.001$ & $<0.001$ & $<0.001$ & 0.98 & 0.69 & 0.70 & 0.29 \\
\hline
\end{tabular}

All values are presented as a median (interquartile range). *p values were calculated using the Student's t-test to compare each measured parameter between the non-slanted and slanted groups. NFS, nasal floor slanting; NSD, nasal septal deviation; IOr, most inferior point of the orbit; IMS, most inferior point of the maxillary sinus
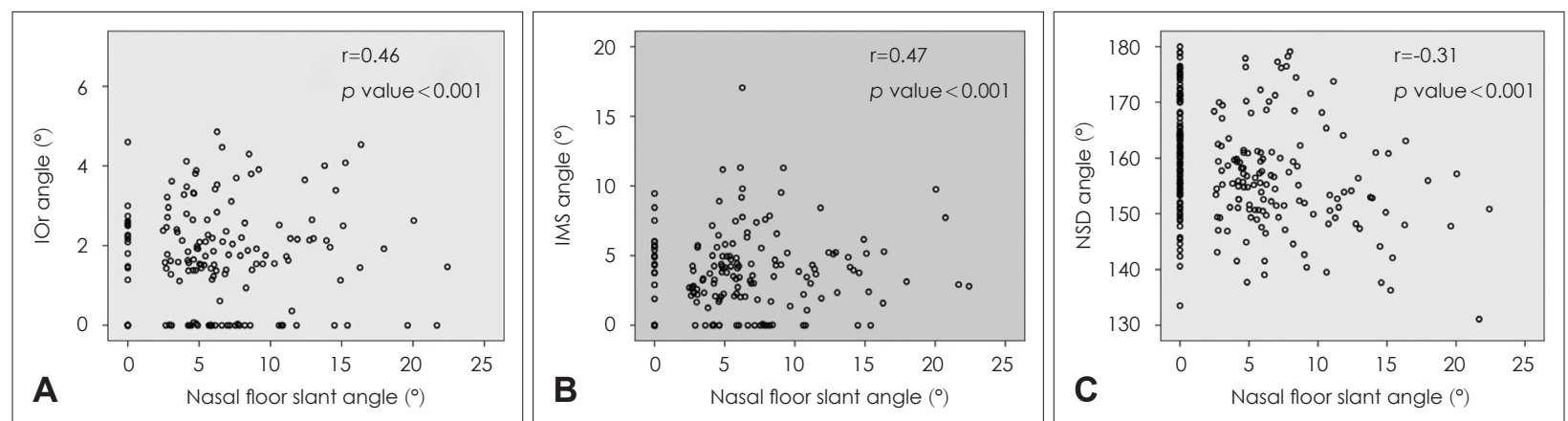

Fig. 4. Linear regression analysis on the degree of nasal floor tilting and the degree of asymmetry of the bony nasofacial structures $(n=265)$. A: A significant positive correlation was observed between the IOr angle and NFS angle. B: A significant positive correlation was observed between the IMS angle and NFS angle. C: A significant negative correlation was observed between the bony NSD angle and NFS angle. IOr, most inferior point of the orbit; NFS, nasal floor slanting; IMS, most inferior point of the maxillary sinus; NSD, nasal septal deviation. 
Table 4. Association of nasofacial abnormalities with the NFS direction in 136 patients with NFS

\begin{tabular}{lcc}
\hline & $\begin{array}{c}\text { On the side of the superiorly } \\
\text { located nasal floor }\end{array}$ & $\begin{array}{c}\text { On the side of the inferiorly } \\
\text { located nasal floor }\end{array}$ \\
\hline $\begin{array}{l}\text { Radiographic finding* } \\
\text { Superiorly located orbit }\end{array}$ & $75(55.1)$ & $26(19.1)$ \\
Superiorly located maxillary sinus & $88(64.7)$ & $21(15.4)$ \\
Smaller maxillary sinus & $54(39.7)$ & $11(8.1)$ \\
Direction of the nasal septum deviation & $45(33.1)$ & $76(55.9)$ \\
Photographic findings & & $46(33.8)$ \\
Superiorly located lateral canthus & $69(50.7)$ & $46(33.8)$ \\
Superiorly located alar base & $54(39.7)$ & $38(27.9)$ \\
Superiorly located angular margin & $71(52.2)$ & $49(36.0)$ \\
Direction of the external nasal deviation & $48(35.3)$ &
\end{tabular}

All values are presented as the number of patients (\%). *detailed description of each facial parameter shown in Fig. 2

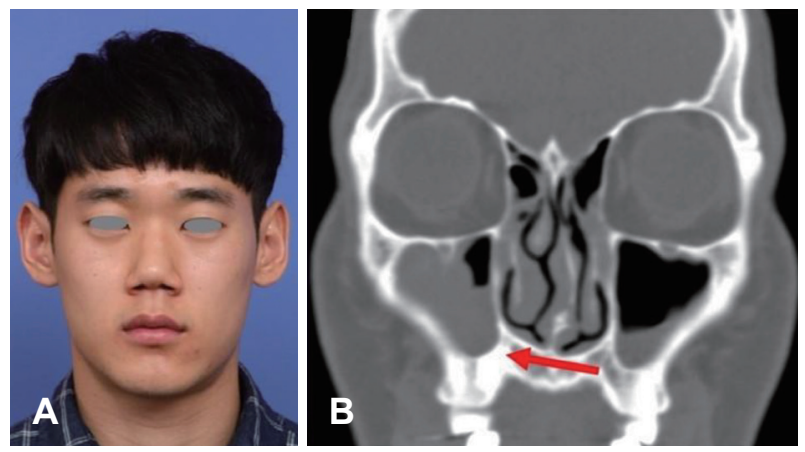

Fig. 5. Frontal photograph and ostiomeatal unit CT image of a 22-year-old male patient showing a higher location of the orbit and maxillary sinus on the right side, in addition to a smaller maxillary sinus on the right side, which was the side of a higher nasal floor. Additionally, the lateral canthus margin and the lateral lip margin presented more superiorly on the right side, whereas no level difference was observed in the alar base levels.

of prior studies. ${ }^{1,5,6)}$ Many authors have also suggested that a septal deformity is a result of asymmetrical growth of the palatal process of the maxilla. ${ }^{7,8)}$ Gray was the first researcher to describe and discuss the asymmetry of the nasal cavity floor levels, suggesting that this asymmetry results from the abnormal development of the maxilla. ${ }^{5)}$ It has also been reported that the palatal edge of the nasal septum tends to be luxated towards the side of lower nasal floor. Mladina ${ }^{1)}$ classified the types of nasal septum deformity according to the presence of asymmetry in the maxilla bone. In that study, it was found that nasal floor asymmetry is always accompanied by an asymmetry in the maxilla bone shape, leading to an instability of the nasal septum anchoring to the palatal process of the maxilla. This in turn increases the vulnerability of the nasal septum in cases of nasal trauma. In addition, the side of the septal abnormality (deviation, ridge, and crista) was shown to be predominantly the lower nasal floor (i.e. more than $73 \%$ of cases).

Our current study was conceptually different from previous investigations in that we mainly focused on defining the incidence of nasal asymmetry, measuring it quantitatively, and assessing its relationship with adjacent nasofacial structures. Nevertheless, it was interesting that we obtained very similar findings to previous publications. The incidence of the NFS was shown to be $51 \%$ in our study series by CT imagery, whereas an incidence of 52\% was described using rhinoscopic inspection by Mladina. ${ }^{1)}$ Moreover, our results are in line with those of Mladina ${ }^{1)}$ and Gray. ${ }^{5)}$ in showing that the bony nasal septum tends to be deviated to the side of the lower nasal floor (76/136 patients [56\%]). In those previous studies, the information was limited to structural abnormalities of the nasal septum and its anchoring to the palatal aspect of the maxilla. By contrast, we have investigated the spatial relationship between the bony nasal septum and the maxillary sinus, along with the asymmetry of the nasal floor levels. As indicated in Table 3 in our present study, the bony components of the maxilla (orbit and maxillary sinus) tend to be parallel with the slanting of the nasal floor. In addition, we observed that a smaller maxillary sinus was more prone to be on the higher nasal floor side. This observation could be explained by the fact that the mean IOr angle $\left(1.7^{\circ}\right)$ was lower than the mean IMS angle $\left(3.5^{\circ}\right)$ in these cases, which indicated a more profound asymmetry in the middle part of the maxilla (represented by the IMS) than the upper part (represented by the IOr), thereby resulting in a smaller maxillary sinus on the side of the higher nasal floor.

To better understand the etiology of NFS in association with the increased rate of facial skeleton deformities, it will crucial to understand the developmental processes for the maxillary bone and the nasal septum. The nasal floor is supported by the palatal process of the maxilla, and its growth is a combination of bony resorption on the nasal side, along with the bony apposition over the oral surface. ${ }^{1)}$ The rapid growth of the maxilla 
and palate is maintained throughout its maturation, and sometimes continues into adulthood. ${ }^{9)}$ It has been found that in people with oral respiration, the palatal growth toward the superior direction is accelerated, thereby resulting in the high palatal arch and abnormal facial appearance. ${ }^{10-13)}$ On the other hand, the most rapid inferior expansion of the maxillary sinus takes place from the ages of 7 to $12 .{ }^{14)}$ In a similar fashion, the ossification of the vomer and perpendicular plate of the ethmoid rapidly progresses from birth until the age of 10 , followed by a slower growth. ${ }^{15,16)}$ Because the maxillary sinus and the bony nasal septum reaches its maximal growth at the age of 12 , while the palate and maxilla are still under rapid growth past this age, an acquired sinonasal pathology causing increased oral breathing might result in an increase in abnormal palatal elevation, leading to a higher chance of an asymmetry of the palate. If the palatal elevation occurs unevenly in both sides, a nasal floor level asymmetry will result, and both maxillary sinus levels will also be uneven, resulting in an increased asymmetry at both the IOr and IMS levels in NFS patients, as shown in our current study series. Likewise, an asymmetrical palatal height may shift the vomer to the less-elevated palate side (to the lower nasal floor side), resulting in a bony NSD toward the side of the lower nasal floor, as already proposed in the study by Gray. ${ }^{5)}$ The correlation we found in our present analyses between the increased degree of asymmetry and the increased NFS strongly suggests that the cephalocaudal pressure caused by a palatal elevation may lead to a deformity of the nasal skeleton (Fig. 4).

We can thus speculate that both NFS and asymmetry in other nasofacial components are a consequence of unknown developmental events from late adolescence to early adulthood. Numerous sinonasal conditions, such as NSD, chronic rhinosinusitis, nasal polyposis, and allergic rhinitis can cause increased oral breathing.

In 2015, Yi and Jang ${ }^{17)}$ reported that a significantly higher incidence of facial asymmetry among patients with a deviated nose (55\%), compared with patients who did not have any deviation of the external nose (32\%). In a similar manner, we aimed in our current analyses to identify whether NFS is associated with facial asymmetry. Our results indicated horizontal facial asymmetry in 81 out of our 265 patients (30.6\%), with a statistically higher proportion found within the NFS group ( $p$ value $=0.01$ ), suggesting an association between facial asymmetry with NFS. However, the proportion of the subjects showing an external nose deviation was not equivalent to that of NFS. These data suggest that compared with bony skel- eton measurements, soft tissue measurements show a much weaker correlation with NFS. Of note in this regard, the level asymmetry of each facial subunit and overall facial volume are thought to be influenced more by the facial expression muscles than the underlying skeletal components.

This study had some limitations of note. First, the enrolled patients all had sinonasal symptoms and this cohort was therefore not representative of the general population. Moreover, since patients under 20 years of age were excluded from our current analyses, our data cannot be readily applied to pediatric or adolescent populations. Further investigations should be conducted regarding on the clinical significance and the impact of NFS upon delivering surgeries on the nasofacial region. Starting with the basic information provided in this article, the authors suggest future studies should be conducted to elucidate the etiology of NFS, and compare rhinoplasty or septoplasty outcomes between slanted and non-slanted cases.

In conclusion, NFS is present in approximately half of patients with sinonasal symptoms and is significantly associated with an inferiorly located maxillary sinus along with the orbit, smaller maxillary sinus, and NSD towards the lower nasal floor side. NFS patients are likely to show a higher-looking face on the higher nasal floor side.

\section{Acknowledgments}

None.

\section{Author Contribution}

Conceptualization: all authors. Data curation: all authors. Formal analysis: all authors. Funding acquisition: Marn Joon Park, Yong Ju Jang. Investigation: all authors. Methodology: Marn Joon Park, Yong Ju Jang. Project administration: Marn Joon Park, Yong Ju Jang. Resources: all authors. Software: Marn Joon Park, Yong Ju Jang. Supervision: Yong Ju Jang. Validation: Marn Joon Park, Yong Ju Jang. Visualization: Marn Joon Park, Yong Ju Jang. Writingoriginal draft: Marn Joon Park. Writing - review \& editing: Marn Joon Park, Yong Ju Jang.

\section{ORCIDs}

Yong Ju Jang

Marn Joon Park

https://orcid.org/0000-0001-7631-0388

https://orcid.org/0000-0003-1746-3266

\section{REFERENCES}

1) Mladina R. The role of maxillar morphology in the development of pathological septal deformities. Rhinology 1987;25(3):199-205.

2) Orlandi RR. A systematic analysis of septal deviation associated with rhinosinusitis. Laryngoscope 2010;120(8):1687-95.

3) Özkiriş M, Gencer ZK, Aydin R, Açikgöz M, Saydam L. Olfactory bulb volume changes in patients with nasal septal deviation. J Craniofac Surg 2017;28(3):e203-7.

4) Uchida Y, Goto M, Katsuki T, Soejima Y. Measurement of maxillary sinus volume using computerized tomographic images. Int J Oral Maxillofac Implants 1998;13(6):811-8. 
5) Gray LP. Prevention and treatment of septal deformity in infancy and childhood. Rhinology 1977;15(4):183-91.

6) Quante M, Franzen G, Strauss P. The correlation between permanent septal deformities and nasal trauma during birth. Rhinology 1976; 14(3):141-6.

7) Fields HW, Sinclair PM. Dentofacial growth and development. ASDC J Dent Child 1990;57(1):46-55.

8) Reitzen SD, Chung W, Shah AR. Nasal septal deviation in the pediatric and adult populations. Ear Nose Throat J 2011;90(3):112-5.

9) Akbay E, Cokkeser Y, Yilmaz O, Cevik C. The relationship between posterior septum deviation and depth of maxillopalatal arch. Auris Nasus Larynx 2013;40(3):286-90.

10) Bresolin D, Shapiro PA, Shapiro GG, Chapko MK, Dassel S. Mouth breathing in allergic children: Its relationship to dentofacial development. Am J Orthod 1983;83(4):334-40.

11) Paradise JL, Bernard BS, Colborn DK, Janosky JE. Assessment of adenoidal obstruction in children: Clinical signs versus roentgenographic findings. Pediatrics 1998;101(6):979-86.
12) Serter S, Günhan K, Can F, Pabuşçu Y. Transformation of the maxillary bone in adults with nasal polyposis: A CT morphometric study. Diagn Interv Radiol 2010;16(2):122-4.

13) Tomer BS, Harvold EP. Primate experiments on mandibular growth direction. Am J Orthod 1982;82(2):114-9.

14) Jun BC, Song SW, Park CS, Lee DH, Cho KJ, Cho JH. The analysis of maxillary sinus aeration according to aging process; volume assessment by 3-dimensional reconstruction by high-resolutional CT scanning. Otolaryngol Head Neck Surg 2005;132(3):429-34.

15) Kim J, Cho JH, Kim SW, Kim BG, Lee DC, Kim SW. Anatomical variation of the nasal septum: Correlation among septal components. Clin Anat 2010;23(8):945-9.

16) Van Loosen J, Van Zanten GA, Howard CV, Verwoerd-Verhoef HL, Van Velzen D, Verwoerd CD. Growth characteristics of the human nasal septum. Rhinology 1996;34(2):78-82.

17) Yi JS, Jang YJ. Frequency and characteristics of facial asymmetry in patients with deviated noses. JAMA Facial Plast Surg 2015;17(4): 265-9. 